\title{
Inhibition of Wnt activity induces heart formation from posterior mesoderm
}

\author{
Martha J. Marvin, ${ }^{1}$ Giuliana Di Rocco, ${ }^{1}$ Aaron Gardiner, ${ }^{1}$ Sara M. Bush, ${ }^{2,3}$ and Andrew B. Lassar ${ }^{1,4}$ \\ ${ }^{1}$ Department of Biological Chemistry and Molecular Pharmacology, Harvard Medical School, Boston, Massachusetts 02115, \\ $\mathrm{USA}^{2}{ }^{2}$ Whitehead Institute for Biomedical Research and Massachusetts Institute of Technology, Cambridge, Massachusetts \\ 02142, USA
}

In the chick, heart mesoderm is induced by signals from the anterior endoderm. Although BMP-2 is expressed in the anterior endoderm, BMP activity is necessary but not sufficient for heart formation. Previous work from our lab has suggested that one or more additional factors from anterior endoderm are required. Crescent is a Frizzled-related protein that inhibits Wnt-8c and is expressed in anterior endoderm during gastrulation. At the same stages, expression of Wnt-3a and Wnt-8c is restricted to the primitive streak and posterior lateral plate, and is absent from the anterior region where crescent is expressed. Posterior lateral plate mesoderm normally forms blood, but coculture of this tissue with anterior endoderm or infection with RCAS-crescent induces formation of beating heart muscle and represses formation of blood. Dkk-1, a Wnt inhibitor of a different protein family, similarly induces heart-specific gene expression in posterior lateral plate mesoderm. Furthermore, we have found that ectopic Wnt signals can repress heart formation from anterior mesoderm in vitro and in vivo and that forced expression of either Wnt-3a or Wnt-8c can promote development of primitive erythrocytes from the precardiac region. We conclude that inhibition of Wnt signaling promotes heart formation in the anterior lateral mesoderm, whereas active Wnt signaling in the posterior lateral mesoderm promotes blood development. We propose a model in which two orthogonal gradients, one of Wnt activity along the anterior-posterior axis and the other of BMP signals along the dorsal-ventral axis, intersect in the heart-forming region to induce cardiogenesis in a region of high BMP and low Wnt activity.

[Key Words: Crescent; Dkk-1; Wnt; heart induction; endoderm; erythropoiesis]

Received September 28, 2000; revised version accepted December 7, 2000.

The heart and the derivatives of the blood islands are the first mesodermal tissues to differentiate after gastrulation in amniote embryos. Cells that migrate anterior and lateral to the primitive streak in early gastrulation contribute to heart tissue, whereas cells that move into the posterior lateral plate form the extraembryonic blood islands (Rosenquist and DeHaan 1966; Schoenwolf et al. 1992; Garcia-Martinez and Schoenwolf 1993). Precardiac cells residing in the primitive streak at stage 3 are uncommitted (Inagaki et al. 1993) but become specified in response to signals from surrounding tissues after their migration into the lateral plate (Antin et al. 1994; Montgomery et al. 1994; Sugi and Lough 1994; Schultheiss et al. 1995, 1997). The cardiac mesoderm precursors are in contact with presumptive anterior endoderm throughout their migration from the streak into the lateral plate (Garcia-Martinez and Schoenwolf 1993). Anterior endoderm is required for cardiac specification in Xenopus

\footnotetext{
${ }^{3}$ This article is dedicated to the memory of our colleague and friend Sara Mae Bush (May 14, 1972-June 22, 2000).

${ }^{4}$ Corresponding author.

E-MAIL andrew_lassar@hms.harvard.edu; FAX (617) 738-0516.

Article and publication are at www.genesdev.org/cgi/doi/10.1101/ $\operatorname{gad} .855501$.
}

(Nascone and Mercola 1995). Moreover, blood precursors from the posterior primitive streak develop into cardiac myocytes when cultured with anterior but not posterior endoderm (Schultheiss et al. 1995). These findings suggest that the anterior endoderm secretes a heart-inducing signal that influences the fate of nascent mesodermal cells.

BMP signals from the lateral regions of the embryo are also required for heart formation (Schultheiss et al. 1997; Andreé et al. 1998). The BMP antagonist noggin blocks cardiogenesis in explants of stage 4 precardiac mesoendoderm and blocks cardiogenesis in vivo when ectopically expressed through stage 7 (Schultheiss and Lassar 1997; Schultheiss et al. 1997; Schlange et al. 2000). Conversely, anterior paraxial mesoderm, which lies medial to the heart-forming region and normally gives rise to head mesenchyme, can be induced to express cardiac genes and to form beating cardiac myocytes in explant culture by exposure to BMP-2 at stages 5-6 (Schultheiss et al. 1997; Andreé et al. 1998). In vivo, implantation of a BMP-2-soaked bead into the anterior paraxial mesoderm induces the expression of Nkx-2.5 and GATA-4 (Schultheiss et al. 1997; Schlange et al. 2000). While BMP signals can induce robust cardiac differentiation from an- 
terior gastrula stage mesendoderm, posterior mesoderm fails to activate heart markers in response to BMP signals (Schultheiss et al. 1997). These findings led us to propose a two-factor model for heart induction, in which a signal from the anterior endoderm induces a field of cardiogenic competence, and a BMP signal specifies the lateral portion of this field to develop into heart tissue (Schultheiss and Lassar 1997; Schultheiss et al. 1997).

Studies in Xenopus indicate that aspects of embryonic anteroposterior patterning are modulated by Wnt signals. Ectopic expression of FrzB, a Wnt-8 antagonist, expands cement gland and inhibits posterior development in Xenopus (Leyns et al. 1997; Wang et al. 1997). In contrast, zygotically transcribed XWnt-8 promotes convergent extension movements and the development of ventral and posterior structures, including blood and somites (Christian and Moon 1993; Hoppler et al. 1996; Hoppler and Moon 1998). A second class of Wnt antagonists represented by Dkk-1 also inhibits Wnt- 8 signaling at the extracellular level and has effects similar to those of FrzB on the Xenopus embryo (Glinka et al. 1998).

Although it is clear from these studies that modulation of Wnt signaling can control specification of anteroposterior identity in vertebrates, the effect of Wnt signaling on the induction of heart muscle has not yet been evaluated. Crescent is a member of the FrzB family of Wnt antagonists that is expressed in chick anterior endoderm during gastrulation, while this tissue displays heart-inducing activity (Schultheiss et al. 1995; Pfeffer et al. 1997). During this period, cells in the primitive streak and posterior mesoderm express both Wnt-3a and Wnt$8 \mathrm{c}$. The heart develops from mesoderm derived from the primitive streak, and thus, the cardiac precursor cells themselves expressed Wnt genes at an earlier stage of development.

In this work, we demonstrate that the absence or presence of Wnt signals controls the specification of cardiac tissue and embryonic blood in anterior and posterior mesoderm, respectively. Administration of exogenous crescent or Dkk-1 to posterior lateral plate mesoderm induces heart muscle formation while repressing erythropoiesis. Conversely, ectopic expression of either Wnt-8c or Wnt-3a in precardiac mesoderm blocks cardiogenesis in this tissue while promoting formation of primitive erythrocytes. On the basis of these findings, we propose a model in which modulation of Wnt activity along the anterior-posterior axis establishes competence to form heart or blood in response to the BMP signals that affect all ventral mesoderm.

\section{Results}

Crescent is a Wnt-8c antagonist expressed in anterior endoderm

To search for signaling molecules in anterior endoderm that might be involved in heart induction, we used a suppression PCR-based cloning method (Diatchenko et al. 1996) to identify transcripts that are expressed in the anterior endoderm but are absent from the posterior primitive streak (PPS) in stage 5-6 chick embryos. A frag- ment of crescent (Pfeffer et al. 1997), a member of the FrzB class of Wnt antagonists (Leyns et al. 1997; Wang et al. 1997), was encoded by $2 \%$ of the subtracted clones. Crescent mRNA is abundant in the anterior hypoblast and anterior definitive endoderm from stage 2 to stage 6 . At stage 5-6, crescent is expressed in prechordal mesendoderm as well, but at stage $6-7$, its expression begins to decline in the endoderm underlying the presumptive heart and head mesoderm (Fig. 1, panels A-C; Pfeffer et al. 1997). Previous work has indicated that heart-inducing activity is present in both medial and lateral regions of stage 3-6 anterior mesoendoderm (Schultheiss et al. 1995, 1997), two regions of the embryo that express crescent transcripts (Fig. 1, panels A-C). In contrast, Wnt-8c is expressed in the primitive streak and in adjacent ectodermal cells at high levels and in the migrating posterior lateral plate (PLP) mesoderm at a relatively lower level (Fig. 1, panels D-F; Hume and Dodd 1993). In addition, Wnt-3a is expressed in the primitive streak from stage 3 (Fig. 1, panels G-I). Thus, crescent and Wnt expression domains are complementary, with crescent in the anterior and Wnt-8c and Wnt-3a in primitive streak and posterior tissues.

To test whether crescent can antagonize Wnt activity, we examined the effect of ectopic crescent expression in injected Xenopus embryos. As with other FrzB-related Wnt antagonists (Leyns et al. 1997; Salic et al. 1997; Wang et al. 1997; Deardorff et al. 1998; Xu et al. 1998; Itoh and Sokol 1999), injection of crescent RNA into the marginal zone of one cell of a two-cell Xenopus embryo enlarged anterior tissues and inhibited posterior extension (Fig. 2A). To directly address whether crescent is a Wnt antagonist, we examined whether crescent could block Wnt-induced expression of the homeobox gene siamois in Xenopus animal caps. Animal caps cut from embryos injected with chick Wnt-8c RNA expressed siamois (Fig. 2B, lane 4). Co-injection of crescent RNA at a sixfold molar ratio to Wnt-8c abolished this response (Fig. 2B, lane 5).

Injection of Wnt-3a RNA also induced expression of siamois in animal caps (Fig. 2B, lane 6). However, in this case, crescent co-injection could only partially dampen induction of siamois by Wnt-3a, reducing its expression threefold in response to a 120:1 molar excess of crescent to Wnt-3a RNA (Fig. 2B, lane 7). Although we do not know the relative steady-state levels of proteins produced by these injected RNAs, these results suggest that crescent is a potent inhibitor of Wnt-8c and a significantly weaker antagonist of Wnt-3a. Furthermore, these results suggest that the anterior expression of crescent and posterior expression of Wnt-8c and Wnt-3a in gastrula stage chick embryos combine to produce a gradient of Wnt activity, with lower levels of Wnt signaling in the anterior and higher levels in the posterior regions of the embryo.

Anterior endoderm induces heart muscle from posterior mesoderm and primitive streak

This laboratory previously demonstrated that anterior endoderm can induce stage 3-6 PPS to form heart muscle (Schultheiss et al. 1995). Here we show that anterior en- 
Marvin et al. orly, whereas Wnt-8c and Wnt-3a are expressed posteriorly in gastrula stage chick embryos. In situ hybridization comparing crescent $(A-C)$, Wnt-8c $(D-F)$, and Wnt-3a $(G-I)$ expression patterns at the indicated gastrulation stages. $(C, F, I)$ Sections of stage 6 embryos are at the levels indicated by the red lines in $B, E$, and $H$, respectively. Crescent expression is restricted to the germinal crescent, anterior endoderm, and prechordal plate. Wnt-8c is expressed in primitive streak and migrating lateral plate mesoderm. Wnt-3a is expressed in the epiblast of the primitive streak. Arrow in $F$ shows expression of Wnt-8c in lateral plate mesoderm.
4
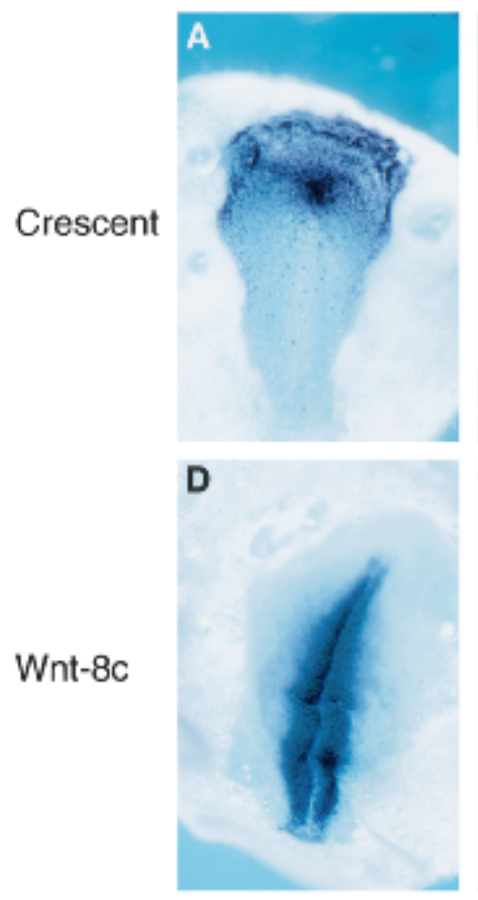

6
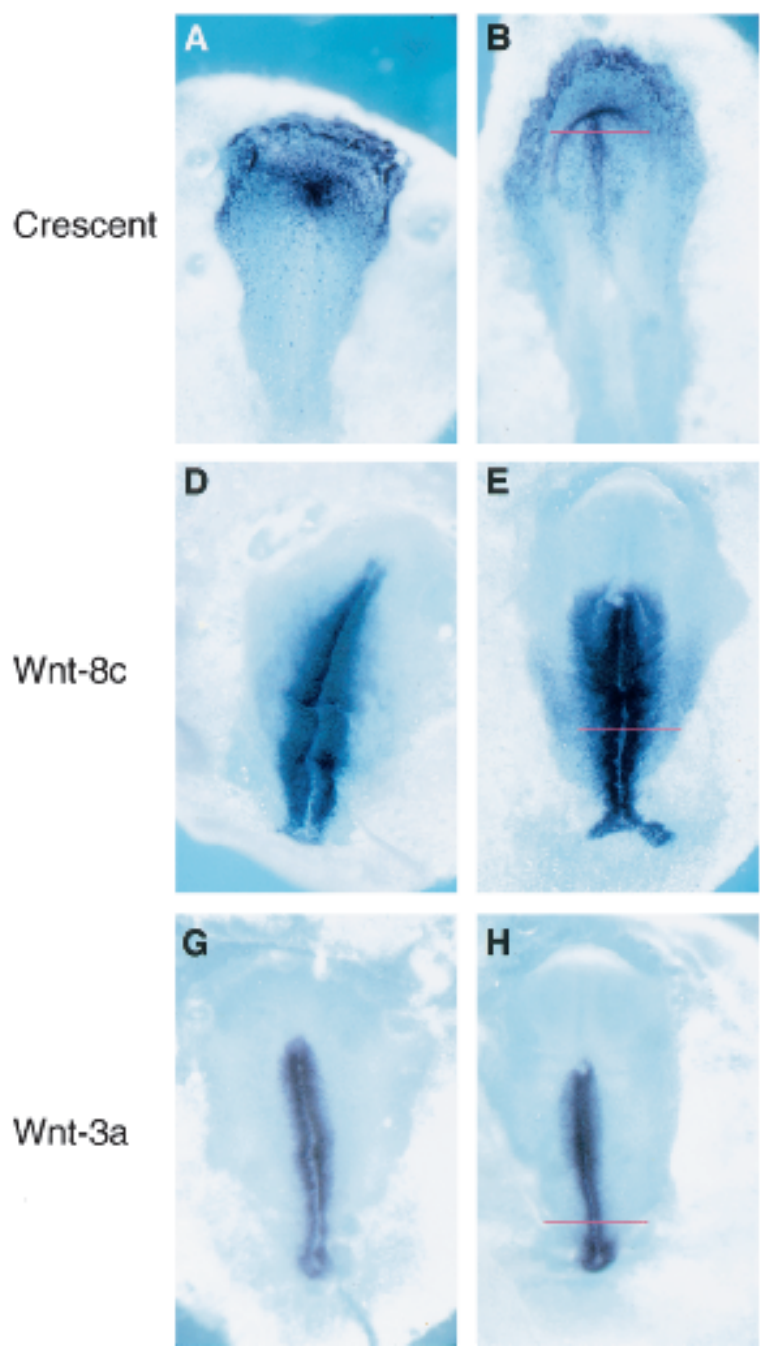

Section
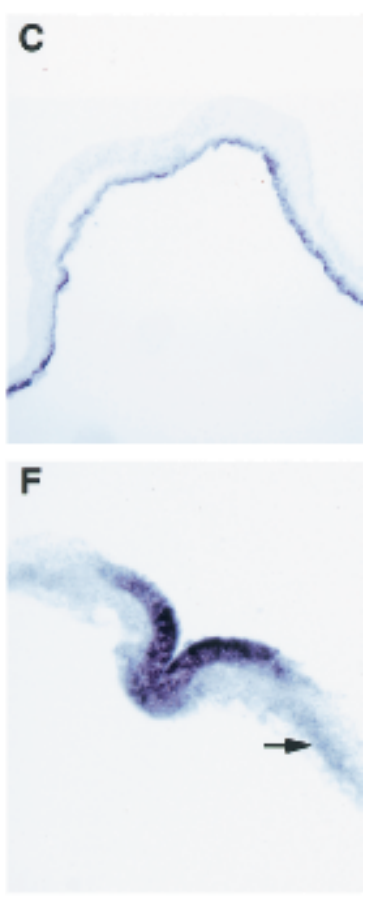

I

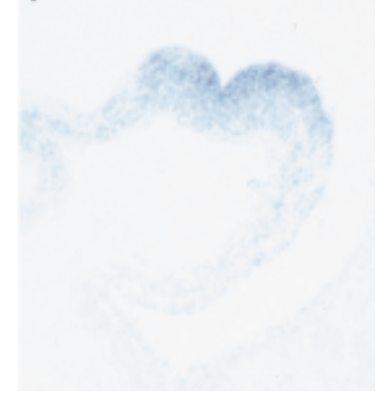

doderm has a similar effect on stage $4^{+}-6$ posterior lateral plate (PLP) mesoderm. PLP mesoderm is a developmentally more advanced target tissue than PPS. This tissue contains cells that are fated to become solely mesodermal derivatives and lacks the epiblast layer present in primitive streak explants. Explants of either chick PLP mesoderm or PPS tissue failed to express any cardiac markers when cultured alone (Fig. 3, lanes 1,3). In contrast, cocultures of these chick posterior tissues with quail anterior lateral mesendoderm from the precardiac region displayed robust expression of both chick and quail Nkx-2.5, ventricular myosin heavy chain (vMHC), and atrial myosin heavy chain (aMHC; Fig. 3, lanes 2,4). Restriction fragment polymorphisms between the chick and quail genes were used to identify the species of the PCR products. Cells in both the PLP mesoderm and the PPS were responsive to the heart-inducing activity of the anterior endoderm. These findings indicate that anterior endoderm contains one or more signals that can induce cardiogenesis in either PPS tissue or PLP mesoderm, neither of which normally gives rise to heart.
Crescent or Dkk-1 expression converts posterior mesoderm to heart muscle

As crescent is expressed in anterior endoderm at approximately the stage expected for a heart-inducing factor, we investigated whether this Wnt inhibitor could induce the formation of heart muscle in explanted gastrulastage posterior tissues. We made a replication-competent RCAS-crescent retrovirus and examined whether viral crescent expression can substitute for anterior endoderm in the cardiac induction assay. Explants of either PLPmesoderm or PPS were infected with RCAS viruses encoding either crescent (RCAS-crescent) or alkaline phosphatase (RCAS-AP).

RCAS-AP infected explants of PLP mesoderm expressed the primitive erythrocyte marker, $\rho$-globin, and lacked cardiac gene expression (Fig. 4A, lane 1). In contrast, PLP mesoderm explants infected with RCAS-crescent expressed numerous heart markers including Nkx2.5, vMHC, aMHC, GATA-4, and cardiac myosin heavy chain-1 (CMHC1) and began to beat rhythmically within 


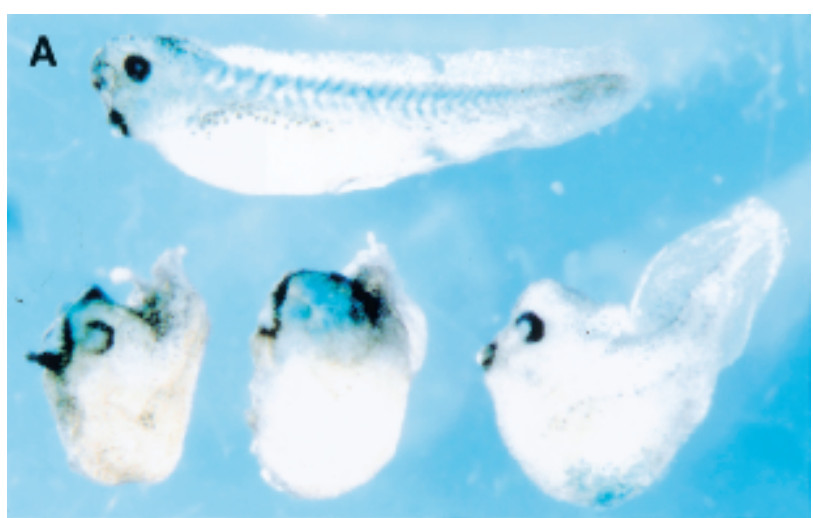

B
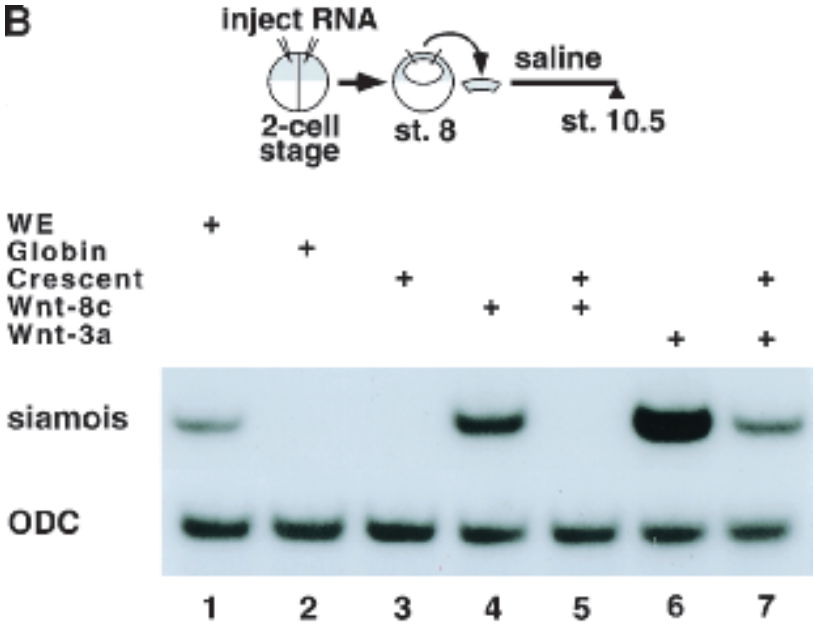

Figure 2. Crescent is an efficient Wnt- 8 antagonist. (A) Crescent injection into one cell of a two-cell embryo enlarged anterior structures and inhibited posterior extension in injected Xenopus embryos (bottom series of embryos). Control embryos (top) were injected with globin mRNA. LacZ mRNA was included as a lineage tracer. $(B)$ Crescent inhibited the induction of siamois by chick Wnt-8c in Xenopus animal caps. RT-PCR analysis of siamois and ornithine decarboxylase (ODC) expression in whole embryos (WE; lane 1) or animal caps from embryos injected with the following RNAs: globin RNA (lane 2), 1 ng of crescent RNA (lane 3), 200 pg of chick Wnt-8c RNA (lane 4), $200 \mathrm{pg}$ of chick Wnt-8c and $1 \mathrm{ng}$ of crescent RNA (lane 5), 10 pg of mWnt-3a (lane 6), or $10 \mathrm{pg}$ of mWnt-3a and $1 \mathrm{ng}$ of crescent (lane 7). All injected RNA was made up to $1.2 \mathrm{ng}$ with globin RNA. The difference between the levels of siamois expression in lanes 6 and 7 was approximately threefold, when normalized to ODC levels.

$48 \mathrm{~h}$ of infection (Fig. 4A, lane 2). CMHC1 is a myosin isoform that is expressed exclusively within the heart (Croissant et al. 2000). As found for heart induction by endoderm (Schultheiss et al. 1995), RCAS-crescent reduced the expression of $\rho$-globin in explants of PLP mesoderm. These results are summarized in Table 1. Like the PLP mesodermal explants, PPS explants formed $\rho$-globin-expressing cells when infected with RCAS-AP (Fig. 4A, lane 3). However, in contrast to the strong cardiogenic response of PLP mesoderm to ectopic crescent, PPS explants showed only occasional weak induction of
Nkx-2.5 yet no detectable expression of myosin or beating in response to RCAS-crescent infection (Fig. 4A, lane 4).

Although signals from the anterior endoderm can induce a cardiogenic response in both PPS and PLP mesoderm, crescent administration elicited cardiogenesis only in PLP mesoderm. These findings suggest that the signaling requirements necessary for heart induction differ between PLP mesoderm and PPS. PPS explants contain both the ectodermal and mesodermal layers of the streak, whereas PLP explants contain only mesoderm. The streak ectoderm showed the highest concentration of mRNA for both Wnt-3a and Wnt-8c by in situ hybridization (Fig. 1, panels F,I).

Accordingly, PPS expressed higher levels of Wnt-8c and Wnt-3a than PLP mesoderm at the time of dissection (Fig. 4B, cf. lanes 1 and 5). Furthermore, during in vitro culture of these tissues, expression of Wnt- $8 \mathrm{c}$ and Wnt3 a declined to a greater extent in the PLP mesoderm than in PPS (Fig. 4B). The higher level and longer duration of Wnt-3a and Wnt-8c expression in PPS raised the possibility that signaling by these Wnt family members may

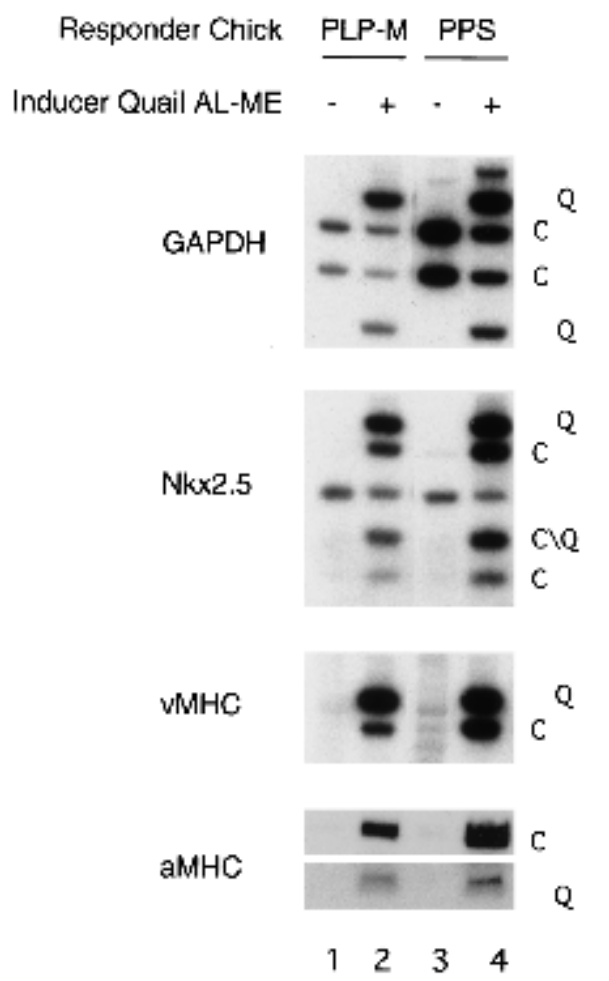

Figure 3. Stage 5 chick posterior lateral plate and posterior primitive streak express heart markers when cocultured with quail anterior endoderm. Stage 5 chick PLP mesoderm was explanted and cultured either alone (lane 1) or in the presence of quail anterior endoderm (lane 2). Stage 5 chick PPS was explanted and cultured either alone (lane 3) or in the presence of quail anterior endoderm (lane 4). Cultures were grown for $48 \mathrm{~h}$ and harvested for RNA. Gene expression for GAPDH, Nkx-2.5, vMHC, and aMHC were assayed for both quail (Q) and chick (C) tissue by RT-PCR. Restriction site polymorphisms were employed to distinguish quail and chick transcripts. 


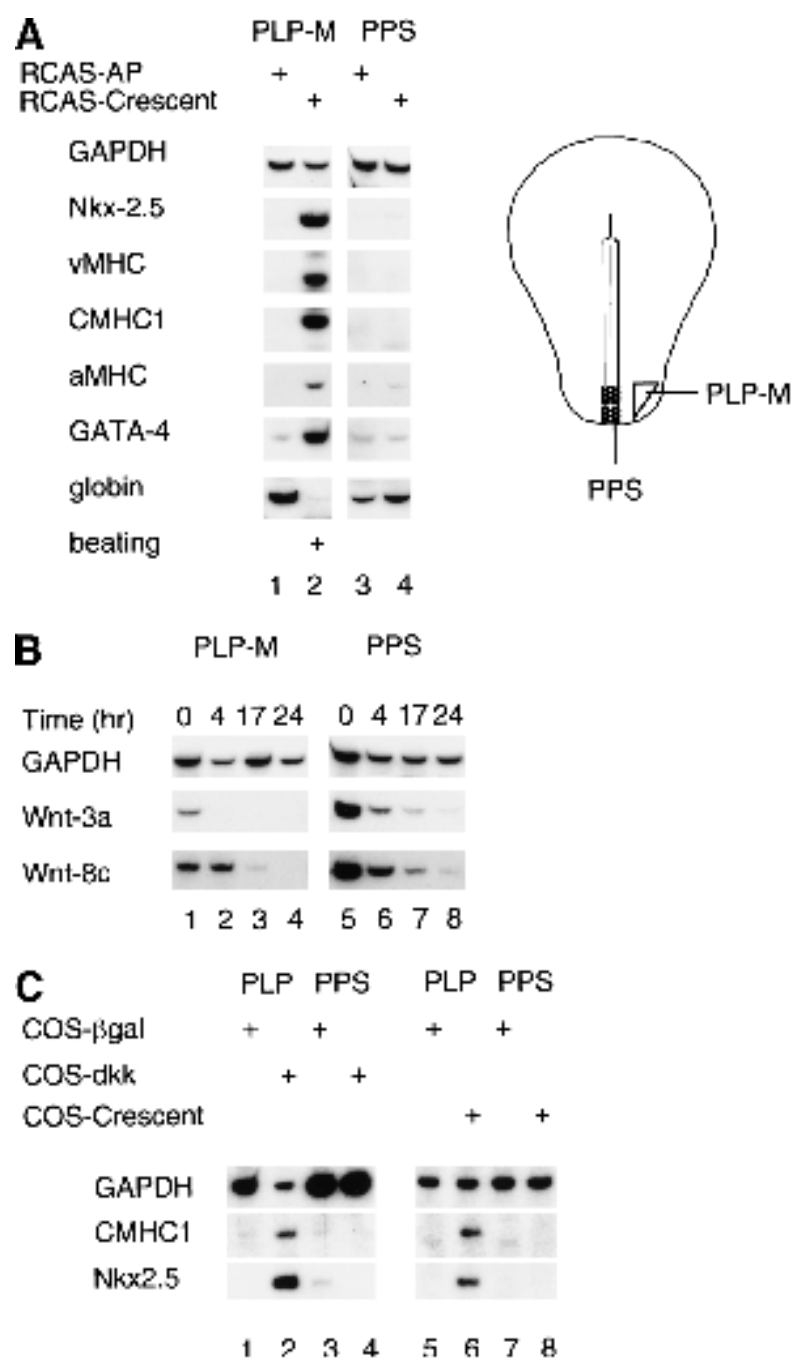

Figure 4. Wht antagonists can induce cardiogenesis in PLP mesoderm but not in PPS explants. (A) Stage 5 posterior lateral plate (PLP) mesoderm (lanes 1,2) or posterior primitive streak (lanes 3,4) were infected with RCAS viruses encoding either alkaline phosphatase (AP; lanes 1,3) or crescent (lanes 2,4). Gene expression for the indicated genes was assayed by RT-PCR analysis. (B) Time course of Wnt-8c and Wnt-3a expression in stage 5 PLP and PPS mesoderm explants. PLP mesoderm (lanes 1-4) or PPS (lanes 5-8) were cultured for the indicated periods of time. At the end of the culture period, explants were harvested and transcript levels evaluated by RT-PCR. (C) Posterior tissues cocultured with COS cells expressing pCS2+- $\beta$-gal, pCMVDkk-1 (Xenopus), or pCS2+-crescent. PLP mesoderm (lanes $1,2,5,6$ ) or PPS (lanes $3,4,7,8$ ) were cultured with either control COS cells expressing CS2 $2^{+}-\beta$-gal (lanes $\left.1,3,5,7\right)$, COS cells expressing pCMV2-XDkk-1 (lanes 2,4), or COS cells expressing pCS2 $2^{+}$-crescent (lanes 6,8). Transcript levels for the indicated genes were evaluated by RT-PCR.

prevent the induction of cardiac gene expression in PPS by ectopic Wnt antagonists.

Because PPS contains considerably more Wnt-3a mRNA than does PLP-mesoderm, and crescent is a relatively weak antagonist of this Wnt family member (Fig. 2B), we wondered if higher levels of Wnt-3a in the PPS could be blocking the cardiogenic effects of crescent in this tissue.

To explore this possibility, we evaluated whether expression of Dkk-1, another class of Wnt antagonist that inhibits both Wnt-8 and Wnt-3a signals (Kazanskaya et al. 2000; Krupnik et al. 2000), could activate cardiogenesis in either PLP-mesoderm or PPS tissues. COS cells transiently transfected with a plasmid encoding Xenopus Dkk-1 induced both Nkx2.5 and CMHC1 in cocultured PLP mesoderm (Fig. 4C, lane 2). In contrast to PLP mesoderm, cells of the posterior primitive streak failed to activate cardiac gene expression in response to Dkk-1 (Fig. 4C, lane 4). Under the same conditions, COS cells expressing crescent also induced $\mathrm{Nkx}-2.5$ and $\mathrm{CMHC} 1$ expression in PLP mesoderm (Fig. 4C, lane 6) but not in PPS tissue (Fig. 4C, lane 8). Because both crescent and Dkk-1 can induce cardiac gene expression in PLP mesoderm but not in PPS, it seems most likely that repression of Wnt-8c and Wnt-3a activity is sufficient to induce cardiogenesis in the PLP mesoderm but not in the PPS.

\section{Ectopic expression of Wnts blocks cardiogenesis from precardiac mesoderm}

As inhibition of Wnt signaling can induce cardiogenesis in the PLP mesoderm, we hypothesized that expression of Wnt signals in the heart field would have the opposite effect. To address this issue, we examined whether ectopic expression of Wnt-3a in the presumptive heart field affects the expression of Nkx-2.5 in vivo. Embryos in which a pellet of chick embryo fibroblasts infected with RCAS-Wnt-3a (Kengaku et al. 1998) was implanted showed a marked decrease in the expression of Nkx-2.5 on the experimental side (Fig. 5A,B). Contralateral control cell pellets did not affect Nkx-2.5 expression (Fig.

Table 1. Effect of RCAS-crescent infection on gene expression in posterior lateral plate mesoderm explants

\begin{tabular}{lccccc}
\hline & \multicolumn{5}{c}{ Expression of markers } \\
\cline { 2 - 6 } Markers & $n$ & Increase & $\begin{array}{c}\text { No } \\
\text { change }\end{array}$ & Decrease & $\begin{array}{c}\text { Not } \\
\text { expressed }\end{array}$ \\
\hline Nkx & 17 & $94 \%$ & $6 \%$ & $0 \%$ & $0 \%$ \\
vMHC & 17 & $82 \%$ & $6 \%$ & $0 \%$ & $12 \%$ \\
CMHC1 & 17 & $82 \%$ & $6 \%$ & $0 \%$ & $12 \%$ \\
aMHC & 17 & $88 \%$ & $12 \%$ & $0 \%$ & $0 \%$ \\
GATA-4 & 17 & $71 \%$ & $29 \%$ & $0 \%$ & $0 \%$ \\
Beating & 23 & $78 \%$ & $0 \%$ & $0 \%$ & $22 \%$ \\
Globin & 17 & $0 \%$ & $18 \%$ & $53 \%$ & $29 \%$ \\
\hline
\end{tabular}

Percentage of posterior lateral plate explants that showed an increase or decrease in the expression of various marker genes (relative to GAPDH levels) on infection with RCAS-crescent, as compared to a paired control explant from the same embryo that was infected with RCAS-AP. Not expressed indicates that neither explants infected with RCAS-AP nor with RCAS-crescent expressed any detectable level of the gene indicated. No change indicates that background levels of the gene indicated were detected, but that these were identical in the control and experimental explant. 

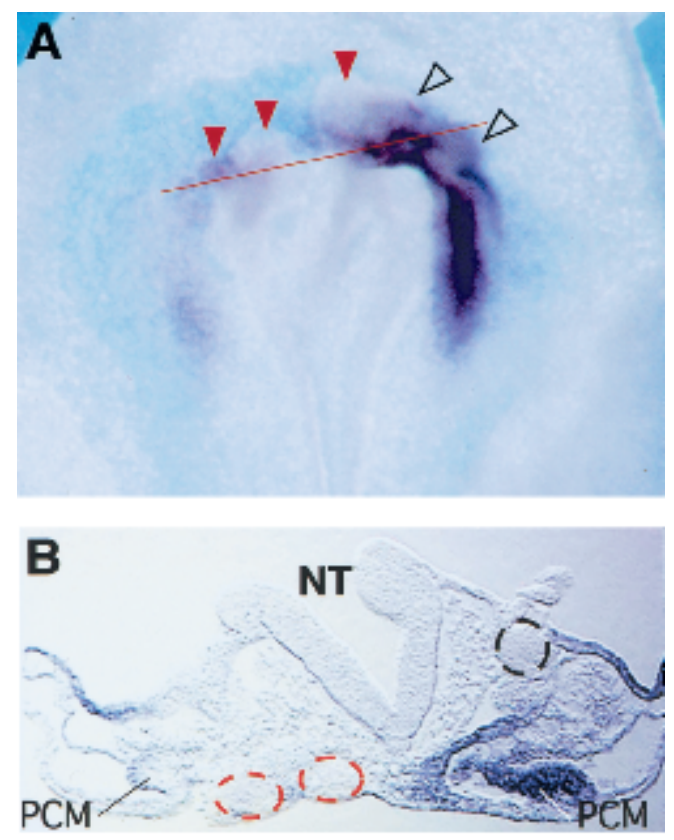

Figure 5. Overexpression of Wnt genes blocks cardiogenesis in precardiac mesoderm. (A) Whole-mount in situ hybridization for Nkx-2.5 in chick embryos in which pellets of chick embryo dermal fibroblasts infected with either RCAS-mWnt-3a or control RCAS-AP were implanted into the precardiac region of embryos in New culture at stage $3^{+}$to 4 . Pellets of RCAS-Wnt-3a infected CEFs (red arrowheads) inhibit expression of Nkx-2.5 in a stage 9 embryo whereas pellets of control RCAS-AP-infected CEFs (open arrowheads) do not. $(B)$ Red line in $A$ indicates the level of this section. RCAS-Wnt3a-expressing cell pellets (red dotted circle) but not control cell pellets (black dotted circle) inhibit expression of cNkx-2.5 in the precardiac mesoderm and foregut endoderm but do not inhibit the accumulation of mesoderm lateral and ventral to the neural tube. $(C)$ Ectopic Wnt expression suppresses cardiogenesis in anterior lateral plate mesoderm explants. Stage 5 anterior lateral plate mesoderm from the precardiac region was infected with either control virus (RCAS-GFP, lane 1; RCAS-AP, lane 3), or RCAS-Wnt-3a (lane 2) or RCAS-Wnt-8c (lane 4). Cultures were carried out in the presence of $200 \mathrm{ng} / \mathrm{mL}$ BMP-4 overnight followed by $48 \mathrm{~h}$ in $20 \mathrm{ng} / \mathrm{mL}$ BMP-4. Transcript levels were evaluated by RT-PCR.
5A,B). Implantation of cells expressing Wnt-1 similarly extinguished endogenous Nkx-2.5 expression in the presumptive heart field (data not shown). These results indicate that Wnt family members can suppress Nkx-2.5 gene expression in developing embryos. However, these in vivo experiments affected all three germ layers. The RCAS-Wnt-3a infected cells distorted the head of the embryo (Fig. 5B), and the neural plate was considerably expanded in some embryos implanted with Wnt-1 or Wnt-3a pellets (data not shown). Therefore, it was unclear whether repression of Nkx-2.5 gene expression by Wnt signals reflected a direct effect on precardiac mesoderm or a secondary effect because of the expansion of the neural plate, which is known to express inhibitors of cardiogenesis (Jacobson 1960; Climent et al. 1995; Schultheiss et al. 1997; Raffin et al. 2000).

To investigate whether Wnt signals can directly modulate cardiac gene expression in mesoderm, we infected explants of stage 5 presumptive heart mesoderm with either RCAS-Wnt-3a or RCAS-Wnt-8c. Heart mesoderm was cultured in serum-free medium containing $200 \mathrm{ng} / \mathrm{mL}$ BMP-4. Inclusion of BMP-4 in the medium supported robust cardiac differentiation from control precardiac mesoderm but was not strictly required for cardiogenesis (data not shown).

Infection of presumptive heart mesoderm with either RCAS-Wnt-3a or RCAS-Wnt-8c inhibited beating of the explants and reduced the expression of cardiac-specific genes in $100 \%(n=7)$ or $76 \%(n=17)$ of the infected explants, respectively (Fig. 5C).

These results indicate that ectopic expression of Wnt$3 \mathrm{a}$ and Wnt-8c, which are both expressed in cells of the primitive streak, can inhibit cardiac gene expression by a direct effect on mesoderm.
Wht signals promote erythrocyte development from precardiac mesoderm

Primitive erythrocytes originate in the yolk sac blood islands that are derived from posterior primitive streak and posterior lateral plate (Rosenquist 1966; Robb 1997; Dieterlen-Lièvre 1998; Palis et al. 1999). Infection of stage 5 precardiac mesoderm with either RCAS-Wnt-3a or RCAS-Wnt-8c promoted expression of the primitive erythrocyte marker $\rho$-globin (Minie et al. 1992) in 43\% $(n=7)$ or $29 \%(n=17)$ of infected explants, respectively (Fig. 5C, lanes 2,4). In contrast, presumptive heart mesoderm from stage 5 embryos failed to express $\rho$-globin when infected with control RCAS viruses in $100 \%$ of such explants $(n=24$; Fig. 5C, lanes 1,3$)$. This result is consistent with our finding that crescent administration to PLP mesoderm abolishes globin expression in this tissue (Fig. 4A, lane 2) and indicates that Wnt signaling is necessary to promote formation of embryonic blood cells. Furthermore, it demonstrates that Wnts and Wnt inhibitors have reciprocal roles in A-P patterning of lateral mesoderm, with inhibition of Wnt signaling promoting an anterior mesodermal fate and high levels of Wnt signaling promoting a posterior mesodermal fate.

\section{Discussion}

\section{Wnt inhibition promotes heart muscle formation} from posterior mesoderm

The ability of the Wnt inhibitors crescent and Dkk-1 to promote cardiogenesis from posterior lateral plate, a region of the embryo that normally forms blood island derivatives, suggests that Wnt inhibitors expressed in anterior endoderm could have a role in normal heart for- 
mation. Conversely, our findings that ectopic expression of either Wnt-3a or Wnt-8c can inhibit cardiac development and promote erythrocyte formation suggest that A-P patterning in the lateral plate mesoderm involves the modulation of Wnt signals along the axis.

Our results suggest a model in which Wnt signals present in nascent mesoderm must be blocked by Wnt antagonists secreted by anterior endoderm to permit the development of heart muscle in the anterior lateral plate of the embryo. In addition to a modulation of Wnt signals, differentiation of lateral plate mesoderm into either an anterior (i.e., heart) or posterior (i.e., blood) cell fate requires concomitant BMP signaling (Dale et al. 1992; Jones et al. 1992; Fainsod et al. 1994; Graff et al. 1994; Maeno et al. 1994; Suzuki et al. 1994; Schultheiss et al. 1997; Andreé et al. 1998; Schlange et al. 2000), which is present only in the lateral (ventral) domains of the embryo. Thus, mesoderm located in regions of the gastrula stage embryo that are exposed to low levels of Wnt signaling and high levels of BMP signals develop into cardiac tissue (illustrated in Fig. 6)

The cells that will give rise to heart muscle migrate out of the primitive streak into anterior lateral plate, moving from a region of high Wnt expression to a region of relatively lower Wnt expression. Wnt-3a and Wnt-8c inhibit heart development in our precardiac mesoderm explant model system, and these Wnts are expressed in the nascent precardiac mesoderm while it resides in the streak. We have demonstrated that crescent is a potent Wnt-8c antagonist and displays considerably less inhibition against Wnt-3a signaling. Recent work on Xenopus crescent suggests that it might also inhibit Wnt-11, although the evidence is indirect (Pera and De Robertis 2000). The ability of crescent to antagonize the activity of these Wnt family members and induce cardiogenesis in PLP mesoderm is consistent with the notion that such
Wnts act to normally block heart formation in posterior mesodermal tissues.

In addition, it is possible that other Wnt family members block ectopic cardiogenesis in posterior mesoderm. Wnt-5a and Wnt-5b have been reported to be expressed in the primitive streak in both mouse and chick (Parr et al. 1993; Baranski et al. 2000). Chick Wnt-11 is expressed in the posterior portion of the precardiac mesoderm at stages $4-5$ but not in the underlying endoderm (Eisenberg et al. 1997). Ectopic expression of either Wnt-5a or Wnt-11 fails to inhibit cardiac differentiation in Xenopus (Schneider and Mercola 2001). Therefore, it is unlikely that antagonism of either Wnt-5a or Wnt-11 signaling is a prerequisite for heart formation. Indeed, Wnt-11-conditioned medium has been reported to promote cardiogenesis in cultured posterior lateral mesoderm (Eisenberg and Eisenberg 1999). The cardiogenic activity of Wnt-11 may reflect the ability of this Wnt family member to block the activity of Wnt-3a and Wnt-8 (Torres et al. 1996). Therefore, Wnt-11 may induce cardiogenesis in posterior mesoderm by acting via a similar pathway as that of crescent and Dkk-1, by blocking the activity of the axis-inducing class of Wnts.

\section{Crescent and Dkk-1 partially mimic the heart inducing activity of anterior endoderm}

Although crescent is expressed in anterior endoderm until stage 6 , anterior endoderm retains heart-inducing potential until at least stage $8^{-}$(G. Di Rocco and A.B. Lassar, unpubl.), suggesting that factors in addition to crescent may contribute to the cardiac-inducing properties of this tissue. Dkk-1 is expressed in foregut endoderm in mouse (Glinka et al. 1998; Monaghan et al. 1999) and has been reported to inhibit Wnt-3a, Wnt-8, Wnt-2b, and
Figure 6. Model of heart and blood inducing signals in early chick mesoderm. (A) BMP-2 and BMP-4 are expressed in the posterior primitive streak and in the lateral (future ventral) regions of the embryo. Wnt inhibitors such as crescent are expressed in the anterior of the embryo, whereas Wnt-3a and Wnt-8c are expressed in the posterior primitive streak and posterior lateral mesoderm. Nkx-2.5 expression appears at stage 5-6 in the region of the embryo where Wnt signals are blocked by crescent (and presumably other Wnt antagonists) and where BMP-2/BMP-4 are expressed. (B) Lateral plate mesoderm precursor cells are induced to become heart tissue by BMP signals that are transduced in the absence of Wnt-3a/Wnt-8c signaling. Conversely, lateral plate mesoderm precursors develop into primitive erythrocytes in the simultaneous presence of both BMP and Wnt-3a/Wnt-8c signals.

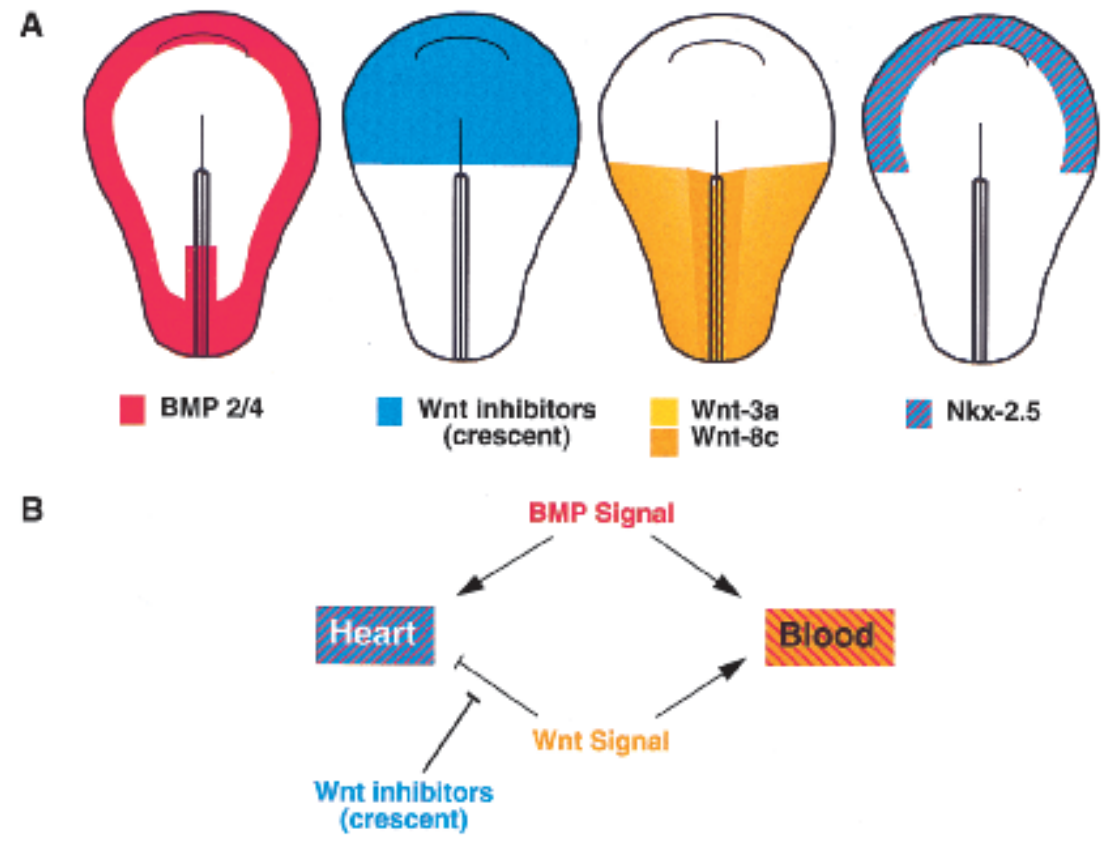


Wnt-5a (Kazanskaya et al. 2000; Krupnik et al. 2000). In our experiments, Dkk-1 acts similarly to crescent and is capable of inducing cardiac gene expression in posterior lateral mesoderm. Whereas signals from the anterior endoderm can elicit cardiogenesis in either PPS or PLP mesoderm, ectopic expression of either crescent or Dkk-1 can induce cardiogenesis only in the latter tissue. This finding indicates that the signaling requirements for cardiogenesis in the PPS versus the PLP mesoderm are different and that anterior endoderm contains factors other than Dkk-1 or crescent that promote cardiogenesis from ingressing mesoderm.

It is possible that anterior endoderm contains both Wnt antagonists and a qualitatively distinct signal that promotes heart formation from PPS. In this scenario, cardiogenic induction of the PPS would require this distinct signal in addition to an anti-Wnt signal, whereas cardiogenesis of the PLP mesoderm would require only an antiWnt signal. Alternatively, anterior endoderm may contain another Wnt antagonist, in addition to crescent and Dkk-1, that is required to elicit cardiogenesis in PPS tissue, which contains higher levels of Wnt-3a and Wnt-8c than does PLP mesoderm. In either case, it seems likely that a component of the cardiogenic signal from the anterior endoderm is a Wnt antagonist(s) that can negate both Wnt-3a and Wnt-8c signaling in cocultured posterior mesodermal tissues.

Although ectopic expression of crescent induced robust formation of heart tissue in explants of posterior lateral mesoderm, in vivo expression of crescent from either a viral vector or pellets of infected cells failed to induce ectopic cardiac marker genes (data not shown). How do we resolve this paradox? It seems most likely that factors in addition to Wnt-8c also repress heart formation in posterior mesoderm in vivo and that these other cardiac repressors are not present or decay rapidly in explanted posterior lateral plate mesoderm. Because posterior mesoderm explants did not contain underlying endoderm or overlying ectoderm, it is possible that these flanking tissues contain a repressor of heart formation that is not blocked by the actions of crescent when administered in vivo. Indeed, mouse visceral endoderm has an activity that can respecify anterior, presumptive neural epiblast as blood (Belaoussoff et al. 1998). Chick posterior endoderm may possess a similar activity that promotes blood formation, blocks heart development, and is not repressed by crescent.

The neural plate/neural tube has long been known to inhibit cardiogenesis (Jacobson 1960; Climent et al. 1995; Schultheiss et al. 1997; Raffin et al. 2000; Tzahor and Lassar 2001). This laboratory has observed that presumptive head mesoderm from stage 8 embryos, when removed from the adjacent inhibitory influence of neural tube, spontaneously differentiates to heart muscle when cultured with foregut endoderm and the overlying nonneural ectoderm (Tzahor and Lassar 2001). Inclusion of neural tube inhibits in vitro cardiogenesis from head mesoderm, but ectopic application of a FrzB-Ig fusion protein and BMP-2 promotes differentiation of heart from the paraxial head mesoderm in spite of the presence of neural tube. Thus, Wnt signals are redeployed during embryogenesis to block ectopic heart formation in differing regions of the vertebrate embryo. During gastrulation stages, Wnt signals in the posterior mesoderm block cardiogenesis and allow this tissue to develop into blood (this study). During neurulation, Wnt signals from the neural tube block cardiogenesis in the anterior paraxial mesoderm and allow this tissue to develop into cranial mesenchyme (Tzahor and Lassar 2001). While in both these instances Wnt signals block ectopic cardiogenesis, the fate of posterior mesoderm versus anterior paraxial mesoderm is distinct and reflects the differential origin of these two tissues.

\section{Other candidate heart-inducing factors}

It has been reported by others that FGF can respecify posterior lateral mesoderm to form heart in combination with BMP-2 (Lough et al. 1996; Ladd et al. 1998). However, the lateral mesoderm in that work extended considerably closer to the heart-forming region, whereas the lateral mesoderm in our assay was located at the extreme posterior of the embryo (at $75 \%-100 \%$ streak length). The combination of BMP-2 and FGF failed to elicit cardiogenesis in this posterior-most mesoderm, although lateral mesoderm located at $50 \%-75 \%$ streak length did activate cardiac gene expression in response to these factors (G. Di Rocco and A. Lassar, unpubl.). However, zebrafish bearing a mutation in FGF-8, normally expressed in the cardiogenic mesoderm, show decreased expression of cardiac markers, indicating that FGF signaling is indeed necessary for heart formation in this species (Riefers et al. 2000).

In addition, it has been reported that ectopic expression of Xenopus cerberus can induce Nkx-2.5 gene expression in injected Xenopus animal cap tissue (Bouwmeester et al. 1996). Cerberus is expressed in the organizer region of Xenopus gastrula stage embryos (Bouwmeester et al. 1996) and can serve as an antagonist of Wnt, BMP, and nodal signaling (Glinka et al. 1997; Hsu et al. 1998; Piccolo et al. 1999). Chick cerberus-1/ caronte is expressed in anterior hypoblast and anterior endoderm but is down-regulated in endoderm by stage 4 (Rodriguez Esteban et al. 1999; Yokouchi et al. 1999; Zhu et al. 1999), whereas the heart-inducing capacity of endoderm is retained in this tissue until at least stage $8^{-}(\mathrm{G}$. Di Rocco and A.B. Lassar, unpubl.). Moreover, in contrast to crescent, which can induce cardiogenesis in cultured PLP mesoderm, ectopic expression of cerberus-1/ caronte fails to promote cardiogenesis in this tissue (A. Gardiner, M. Marvin, and A. Lassar, unpubl.). Together, these data suggest that cerberus-1/caronte is not the cardiac inducing signal(s) of the anterior endoderm.

\section{Evolutionary differences between heart-inducing signals in flies and vertebrates}

Our work highlights a difference between heart formation in flies and vertebrates. Maintenance of the Dro- 
sophila NK-2 gene tinman is required for specification of the cardiac mesoderm, and its expression depends upon the Wnt homologue, wingless (wg), and the BMP homologue, decapentaplegic (dpp; Azpiazu and Frasch 1993; Bodmer 1993; Wu et al. 1995; Park et al. 1996). Similarly, formation of the vertebrate heart requires the tinman related genes Nkx-2.3 or 2.5 (Fu et al. 1998; Grow and Krieg 1998).

However, induction of Nkx-2.5 gene expression depends on the inhibition of Wnt signals (Fig. 4) and exposure to BMP (Schultheiss et al. 1997). A positive role for $d p p / \mathrm{BMP}$ signals has been retained during evolution, but the role of Wnt signaling in heart formation has been reversed. There is accumulating evidence that mechanisms controlling the formation of the fly and vertebrate heart have diverged significantly. Most vertebrate Nkx genes expressed in the heart are able to substitute for the visceral muscle function but not the cardiac-specific function of tinman in Drosophila, because of a requirement for sequences present only in tinman (Park et al. 1998; Ranganayakulu et al. 1998). The precursors to the fly dorsal vessel arise in a metameric pattern from mesoderm derived from the anterior compartment of each segment, whereas the vertebrate precardiac mesoderm arises from a single, bilateral anterior field. These differences in the activity of NK-2 genes, the effects of Wnts on heart formation, and the positional origin of cardiac muscle may reflect the large number of changes in form and function that the heart programs of both vertebrates and flies have undergone independently since they diverged from a basic ancestral program.

\section{A Wht activity gradient from posterior to anterior modulates both ectodermal and mesodermal cell fates}

Mercola and colleagues have previously demonstrated that signals from both the organizer and the deep endoderm are necessary to induce heart in this species (Nascone and Mercola 1995). More recently, this group has shown that Dkk-1 and crescent, which are both expressed in the organizer region, can induce cardiogenesis in ventral marginal zone tissue (Schneider and Mercola 2001). Consistent with the idea that Wnt signaling suppresses cardiogenesis in vivo, Sive and coworkers have shown that ectopic expression of FrzB family members can expand Nkx-2.5 gene expression in Xenopus embryos (Bradley et al. 2000). Together with our own findings, these results suggest that heart induction can only take place in a region of the vertebrate embryo with low Wnt activity. In chick embryos, the anterior endoderm expresses crescent and perhaps other Wnt antagonists, whereas the primitive streak, from which heart precursors are derived, expresses several Wnt family members. This expression pattern of Wnts and their inhibitors establishes a gradient of Wnt activity in the embryo, in which Wnt signaling is low in the anterior and high in the posterior. We propose that repression of Wnt signals, in combination with BMP activity, is necessary to induce heart tissue in anterior mesoderm. Conversely, the presence of Wnt signals, in combination with BMP ac- tivity, is necessary for formation of primitive erythrocytes in posterior mesoderm. Head induction in Xenopus embryos requires the absence of both Wnt signals and BMP signals (Glinka et al. 1997), and ectopic Wnt expression can block the formation of anterior neural tissue in Xenopus (Christian and Moon 1993). Together with our own findings, these observations suggest that induction of anterior cell fates in both ectoderm and mesoderm requires a blockade of Wnt signals. The anterior of the embryo, which is induced by an absence of Wnt signals, is then divided into dorsal (head) and ventral (heart) regions by the absence or presence of BMP signals, respectively.

\section{Materials and methods}

\section{Subtraction}

First- and second-strand cDNA synthesis (Life Technologies) was carried out on the polyA+ fraction of $0.3-0.5 \mu \mathrm{g}$ of total RNA (OligoTex, QIAGEN). The cDNA was digested with Rsa1 and ligated to annealed primer pairs 2Rsa24: AGCACTCTC CAGGTACTCCACGGT and 2Rsa10: ACCGTGGAGT, modified from Braun et al. (1994). cDNA was amplified by PCR: $72^{\circ} \mathrm{C}$ for $5 \mathrm{~min}$; 28 cycles $93^{\circ} \mathrm{C}$ for $30 \mathrm{sec}, 68^{\circ} \mathrm{C}$ for $30 \mathrm{sec}, 72^{\circ} \mathrm{C}$ for 3 min. cDNA was digested with Rsal.

Anterior lateral plate endoderm and posterior primitive streak cDNA were used as target and driver, respectively, in the PCR-Select Subtraction Kit (Clontech). Target concentration was $1.7 \mathrm{ng} / 5 \mu \mathrm{L}$, and the driver/target ratio was $68: 1$ in the first hybridization and 90:1 in the second.

Subtracted clones were amplified at $64^{\circ} \mathrm{C}$ for 27 cycles. The subtracted endoderm was cloned into Bluescript SK+. Duplicate filters containing the subtracted endoderm plasmid library were screened with the library itself as a positive probe and with PPS driver plus PPS subtracted with endoderm as the negative probe. Clones that hybridized strongly or moderately to the positive probe and did not hybridize with the negative probe were sequenced.

\section{RCAS virus}

Crescent was amplified from cDNA from stage 4 anterior endoderm with primers TTTTTTCCATGGGGGCTGCGAG CACGGAGA and TTTTTAAAGCTTTCAGACCTTCCTGC CGGCCTGTT. A PCR product encoding crescent was cut with Ncol and HindIII and cloned into the vector SLAX-13 (Morgan and Fekete 1996), then subcloned into the Cla1 site of RCAS(B). Chick Wnt-8c was amplified from pGEM cWnt-8c with the primers AGTTCCACGCTCGGTCTC CCATGAGAGGCAGCACCTTC and TTGTTAGCAAGCTT CTATCTCCTGTGGCCTTTGT and was cut with $B s a 1$ and HindIII. The fragments were cloned into the Nco and HindIII sites of SLAX-13, and from there into the Cla1 site of RCAS(B). All viruses were produced in line 0 chick dermal fibroblasts as described in Maroto et al. (1997).

\section{Explant cultures}

Eggs were incubated to the given stage (Hamburger and Hamilton 1951), and tissues were dissected with tungsten needles in Tyrodes solution using 1\% agar dishes as a base. Serum-free medium containing insulin, transferrin, and selenium was adapted from Stern and Hauschka (1995) and supplemented with $2 \%$ chick embryo extract (Life Technologies). Virally infected explants were incubated on ice with viral supernatant diluted $1: 1$ with culture medium for $1-2 \mathrm{~h}$, then cultured over- 
night in a sandwich of $35 \%$ collagen pads and overlaid with the above concentration of viral supernatant and medium containing $8 \mu \mathrm{g} / \mathrm{mL}$ polybrene. The following day, $0.25 \mathrm{~mL}$ of culture medium was added to each well. Anterior endoderm and COS cell cocultures were carried out on $2-\mu$ pore size Nucleopore filters floating on culture medium. Similar results were obtained for anterior endoderm induction in collagen gels.

Posterior primitive streak explants were cut from $80 \%-100 \%$ streak length, and posterior lateral plate mesoderm explants were cut from $75 \%-100 \%$ streak length. PLP mesoderm was carefully scraped off the ectoderm after removal of the endoderm. COS cells were transfected with Fugene (Roche). The plasmids transfected were: $\mathrm{pCS} 2^{+}$-n $\beta$-gal, $\mathrm{pCS}^{+}$-crescent, and pCMV2-XDkk-1 (a generous gift of Dr. Christoph Niehrs, DKFZ, Heidelberg, Germany). BMP-4 (R\&D Systems) was added to the viral supernatant at $200 \mathrm{ng} / \mathrm{mL}$ for overnight incubation and at $20 \mathrm{ng} / \mathrm{mL}$ to the culture medium. Cultures were grown for $\sim 64 \mathrm{~h}$ unless otherwise noted.

\section{$R T-P C R$}

RT-PCR was carried out as in Schultheiss et al. (1995). Additional primers were as follows: aMHC (Yutzey et al. 1994), CCGCACCACAGAAGACCAGAT and GGAGGAGCACTTG GCATTGAC; CMHC1 (Croissant et al. 2000), TGACCAGGGTG GAGAAAAG and TTGTCCTCTGGGATTGCACCTG; GAPDH (glyceraldehyde 3-phosphate dehydrogenase), Nkx-2.5, and vMHC were digested as described in Schultheiss et al. (1995). aMHC products were cut with AvaII, such that the chick aMHC PCR product gave two bands at 299 and $190 \mathrm{bp}$, whereas quail aMHC gave bands at $\sim 185,179$, and $125 \mathrm{bp}$. The 299-bp chick product and 125 -bp quail product are shown here. The aMHC primers amplified chick cDNA with greater affinity than quail.

\section{New culture and in situ hybridization}

The albumen was removed from stage 3-4 eggs. A 2.5-cm Fisher P5 filter paper ring was placed on top of the embryo, and the yolk was gently submerged in Pannett-Compton solution. The vitelline membrane was cut around the outside of the paper ring while the yolk was submerged, and the paper and embryo assembly was inverted, washed, and placed in a dish containing $0.3 \%$ glucose, egg white, and agar as described by Sundin and Eichele (1992). Pellets of RatB1A cells or RCAS-infected fibroblasts were placed in the heart-forming region of the embryo and cultured until the stages indicated. Embryos were fixed in $4 \%$ paraformaldehyde in $\mathrm{pH}$ 7.4 PBS and processed for in situ hybridization (Wilkinson 1993).

\section{Acknowledgments}

We would like to dedicate this article to the memory of our colleague Sara Mae Bush (May 14, 1972-June 22, 2000). We gratefully thank Hazel Sive for generously providing her lab and reagents to perform the Xenopus experiments in this paper. We thank Mark Mercola and Valerie Schneider for sharing data before publication; Tom Schultheiss, Mark Mercola, Doug Spicer, Tamara Holowacz, Eldad Tzahor, Kyu-Ho Lee, Charlie Murtaugh, Ram Reshef, Regina Sohn, and Li Zeng for their helpful comments on the experiments and manuscript. We thank Jan Kitajewski for the gift of the Rat1-Wnt-1 and Rat1-Wnt-3a cells, Cliff Tabin for the RCAS-Wnt-3a virus, Jane Dodd for the cWnt-8c clone, Christoph Niehrs for the pCMV-Dkk-1 plasmid, Vicky Rosen and Genetics Institute for kindly supplying BMP $-2 /-4$, and Jeremy Gaw for her assistance in constructing the RCAS-Wnt- $8 \mathrm{c}$ virus. This work was supported by grants to either A.B.L. or Hazel Sive from both the National Science Foundation and the National Institutes of Health. This work was done during the tenure of an established investigatorship from the American Heart Association to A.B.L. M.J.M. was supported by fellowships from the Massachusetts Affiliate of the American Heart Association and by an NRSA from the National Heart, Lung and Blood Institute. G.D.R. was supported by fellowships from the Italian Telethon Foundation and the Human Frontier Science Program Organization.

The publication costs of this article were defrayed in part by payment of page charges. This article must therefore be hereby marked "advertisement" in accordance with 18 USC section 1734 solely to indicate this fact.

\section{References}

Andreé, B., Duprez, D., Vorbusch, B., Arnold, H., and Brand, T. 1998. BMP-2 induces ectopic expression of cardiac lineage markers and interferes with somite formation in chicken embryos. Mech. Dev. 70: 119-131.

Antin, P.B., Taylor, R.G., and Yatskievych, T. 1994. Precardiac mesoderm is specified during gastrulation in quail. Dev. Dyn. 200: 144-154.

Azpiazu, N. and Frasch, M. 1993. tinman and bagpipe: Two homeo box genes that determine cell fates in the dorsal mesoderm of Drosophila. Genes \& Dev. 7: 1325-1340.

Baranski, M., Berdougo, E., Sandler, J.S., Darnell, D.K., and Burrus, L.W. 2000. The dynamic expression pattern of frzb-1 suggests multiple roles in chick development. Dev. Biol. 217: $25-41$.

Belaoussoff, M., Farrington, S.M., and Baron, M.H. 1998. Hematopoietic induction and respecification of A-P identity by visceral endoderm signaling in the mouse. Development 125: 5009-5018.

Bodmer, R. 1993. The gene tinman is required for specification of the heart and visceral muscles in Drosophila. Development 118: 719-729.

Bouwmeester, T., Kim, S., Sasai, Y., Lu, B., and Robertis, E.M.D. 1996. Cerberus is a head-inducing secreted factor expressed in the anterior endoderm of Spemann's organizer. Nature 382: 595-601.

Bradley, L., Sun, B., Collins-Racie, L., LaVallie, E., McCoy, J., and Sive, H. 2000. Different activities of the frizzled-related proteins frzb2 and sizzled2 during Xenopus anteroposterior patterning. Dev. Biol. 227: 118-132.

Braun, B., Frieden, R., Lessnick, S., May, W., and Denny, C. 1994. Identification of target genes for the Ewing's sarcoma EWS/FLI fusion protein by representational difference analysis. Mol. Cell. Biol. 15: 4623-4630.

Christian, J. and Moon, R. 1993. Interactions between Xwnt-8 and Spemann organizer signaling pathways generate dorsoventral pattern in the embryonic mesoderm of Xenopus. Genes \& Dev. 7: 13-28.

Climent, S., Sarasa, M., Villar, J.M., and Murillo-Ferrol, N.L. 1995. Neurogenic cells inhibit the differentiation of cardiogenic cells. Dev. Biol. 171: 130-148.

Croissant, J.D., Carpenter, S., and Bader, D. 2000. Identification and genomic cloning of CMHC1: A unique myosin heavy chain expressed exclusively in the developing chicken heart. J. Biol. Chem. 275: 1944-1951.

Dale, L., Howes, G., Prive, B., and Smith, J. 1992. Bone morphogenetic protein 4: A ventralizing factor in early Xenopus development. Development 115: 573-585.

Deardorff, M.A., Tan, C., Conrad, L.J., and Klein, P.S. 1998. 
Frizzled-8 is expressed in the Spemann organizer and plays a role in early morphogenesis. Development 125: 2687-2700.

Diatchenko, L., Lau, Y.-F., Campbell, A., Chenchik, A., Moqadam, F., Huang, B., Lukyanov, S., Lukanov, K., Gurskaya, N., Sverdlov, E., et al. 1996. Suppression subtractive hybridization: A method for generating differentially regulated or tissue-specific cDNA probes and libraries. Proc. Natl. Acad. Sci. 93: 6025-6030.

Dieterlen-Lièvre, F. 1998. Hematopoiesis: Progenitors and their genetic program. Curr. Biol. 8: R727-R730.

Eisenberg, C.A. and Eisenberg, L.M. 1999. WNT11 promotes cardiac tissue formation of early mesoderm. Dev. Dyn. 216: 45-58.

Eisenberg, C.A., Gourdie, R.G., and Eisenberg, L.M. 1997. Wnt11 is expressed in early avian mesoderm and required for the differentiation of the quail mesoderm cell line QCE-6. Development 124: 525-536.

Fainsod, A., Steinbeisser, H., and De Robertis, E.M. 1994. On the function of BMP-4 in patterning the marginal zone of the Xenopus embryo. EMBO J. 13: 5015-5025.

Fu, Y., Yan, W., Mohun, T., and Evans, S. 1998. Vertebrate tinman homologues XNkx2-3 and XNkx2-5 are required for heart formation in a functionally redundant manner. Development 125: 4439-4449.

Garcia-Martinez, V. and Schoenwolf, G.C. 1993. Primitive streak origin of the cardiovascular system in avian embryos. Dev. Biol. 159: 706-719.

Glinka, A., Wu, W., Onichtchouk, D., Blumenstock, C., and Niehrs, C. 1997. Head induction by simultaneous repression of Bmp and Wnt signalling in Xenopus. Nature 389: $517-$ 519.

Glinka, A., Wu, W., Delius, H., Monaghan, A., Blumenstock, C., and Niehrs, C. 1998. Dickkopf-1 is a member of a new family of secreted proteins and functions in head induction. Nature 391: 357-362.

Graff, J.M., Thies, R.S., Song, J.J., Celeste, A.J., and Melton, D.A. 1994. Studies with a Xenopus BMP receptor suggest that ventral mesoderm-inducing signals override dorsal signals in vivo. Cell 79: 169-179.

Grow, M. and Krieg, P. 1998. Tinman function is essential for vertebrate heart development: Elimination of cardiac differentiation by dominant inhibitory mutants of the tinmanrelated genes, XNkx2-3 and XNkx2-5. Dev. Biol. 204: 187196.

Hamburger, V. and Hamilton, H.L. 1951. A series of normal stages in the development of the chick embryo. J. Morphol. 88: 49-92.

Hoppler, S. and Moon, R.T. 1998. BMP-2/-4 and Wnt-8 cooperatively pattern the Xenopus mesoderm. Mech. Dev. 71: 119129.

Hoppler, S., Brown, J.D., and Moon, R.T. 1996. Expression of a dominant negative Wnt blocks induction of MyoD in Xenopus embryos. Genes \& Dev. 10: 2805-2817.

Hsu, D.R., Economides, A.N., Wang, X., Eimon, P.M., and Harland, R.M. 1998. The Xenopus dorsalizing factor Gremlin identifies a novel family of secreted proteins that antagonize BMP activities. Mol. Cell 1: 673-683.

Hume, C.R. and Dodd, J. 1993. Cwnt-8C: A novel Wnt gene with a potential role in primitive streak formation and hindbrain organization. Development 119: 1147-1160.

Inagaki, T., Garcia-Martinez, V., and Schoenwolf, G.C. 1993. Regulative ability of the prospective cardiogenic and vasculogenic areas of the primitive streak during avian gastrulation. Dev. Dyn. 197: 57-68.

Itoh, K. and Sokol, S.Y. 1999. Axis determination by inhibition of Wnt signaling in Xenopus. Genes \& Dev. 13: 2328-2336.
Jacobson, A.G. 1960. Influences of ectoderm and endoderm on heart differentiation in the newt. Dev. Biol. 2: 138-154.

Jones, C.M., Lyons, K.M., Lapan, P.M., Wright, C.V.E., and Hogan, B.M.L. 1992. DVR-4 (bone morphogenetic protein-4) as a posterior ventralizing factor in Xenopus mesoderm induction. Development 115: 639-647.

Kazanskaya, O., Glinka, A., and Niehrs, C. 2000. The role of Xenopus dickkopf1 in prechordal plate specification and neural patterning. Development 127: 4981-4992.

Kengaku, M., Capdevila, J., Rodriguez-Esteban, C., Pena, J.D.L., Johnson, R., Izpisua-Belmonte, J.C., and Tabin, C.J. 1998. Distinct WNT pathways regulating AER formation and dorsoventral polarity in the chick limb bud. Science 280: 12741277.

Krupnik, V., Sharp, J., Jiang, C., Robison, K., Chickering, T., Amaravadi, L., Brown, D., Guyot, D., Mays, G., Leiby, K., et al. 2000. Functional and structural diversity of the human Dickkopf gene family. Gene 238: 301-313.

Ladd, A., Yatskievych, T., and Antin, P. 1998. Regulation of avian cardiac morphogenesis by activin/TGFb and bone morphogenetic proteins. Dev. Biol. 204: 407-419.

Leyns, L., Bouwmeester, T., Kim, S.-H., Piccolo, S., and De Robertis, E. 1997. Frzb-1 is a secreted antagonist of Wnt signaling expressed in the Spemann Organizer. Cell 88: 747-756.

Lough, J., Barron, M., Brogley, M., Sugi, Y., Bolender, D.L., and Zhu, X.L. 1996. Combined BMP-2 and FGF-4, but neither factor alone, induces cardiogenesis in non-precardiac embryonic mesoderm. Dev. Biol. 178: 198-202.

Maeno, M., Ong, R.C., Suzuki, A., Ueno, N., and Kung, H.F. 1994. A truncated bone morphogenetic protein 4 receptor alters the fate of ventral mesoderm to dorsal mesoderm: Roles of animal pole tissue in the development of ventral mesoderm. Proc. Nat1. Acad. Sci. 91: 10260-10264.

Maroto, M., Reshef, R., Münsterberg, A.E., Koester, S., Goulding, M., and Lassar, A.B. 1997. Ectopic Pax-3 activates MyoD and Myf-5 expression in embryonic mesoderm and neural tissue. Cell 89: 139-148.

Minie, M., Kimura, T., and Felsenfeld, G. 1992. The developmental switch in embryonic r-globin expression is correlated with erythroid lineage-specific differences in transcription factor levels. Development 115: 1149-1164.

Monaghan, A.P., Kioschis, P., Wu, W., Zuniga, A., Bock, D., Poustka, A., Delius, H., and Niehrs, C. 1999. Dickkopf genes are co-ordinately expressed in mesodermal lineages. Mech. Dev. 87: 45-56.

Montgomery, M.O., Litvin, J., Gonzalez-Sanchez, A., and Bader, D. 1994. Staging of commitment and differentiation of avian cardiac myocytes. Dev. Biol. 164: 63-71.

Morgan, B. and Fekete, D. 1996. Manipulating gene expression with replication-competent retroviruses. In Methods in avian embryology (ed. M. Bronner-Fraser), pp. 185-218. Academic Press, San Diego, CA.

Nascone, N. and Mercola, M. 1995. An inductive role for the endoderm in Xenopus cardiogenesis. Development 121: 515-523.

Palis, J., Robertson, S., Kennedy, M., Wall, C., and Keller, G. 1999. Development of erythroid and myeloid progenitors in the yolk sac and embryo proper of the mouse. Development 126: $5073-5084$.

Park, M., Wu, X., Golden, K., Axelrod, J.D., and Bodmer, R. 1996. The wingless signaling pathway is directly involved in Drosophila heart development. Dev. Biol. 177: 104-116.

Park, M., Lewis, C., Turbay, D., Chung, A., Chen, J.-N., Evans, S., Breitbart, R., Fishman, M., Izumo, S., and Bodmer, R. 1998. Differential rescue of visceral and cardiac defects in Drosophila by vertebrate tinman-related genes. Proc. Natl. 
Acad. Sci. 95: 9366-9371.

Parr, B., Shea, M., Vassileva, G., and McMahon, A. 1993. Mouse Wnt genes exhibit discrete domains of expression in the early embryonic CNS and limb buds. Development 119: 247-261.

Pera, E.M. and De Robertis, E.M. 2000. A direct screen for secreted proteins in Xenopus embryos identifies distinct activities for the Wnt antagonists Crescent and Frzb-1. Mech. Dev. 96: 183-195.

Pfeffer, P., DeRobertis, E., and Izpisua-Belmonte, J.-C. 1997. Crescent, a novel chick gene encoding a Frizzled-like Cysteine-Rich Domain, is expressed in anterior regions during early embryogenesis. Int. J. Dev. Biol. 41: 449-458.

Piccolo, S., Agius, E., Leyns, L., Bhattacharyya, S., Grunz, H., Bouwmeester, T., and Robertis, E.D. 1999. The head inducer Cerberus is a multifunctional antagonis of Nodal, BMP and Wnt signals. Nature 397: 707-710.

Raffin, M., Leong, L., Rones, M., Sparrow, D., Mohun, T., and Mercola, M. 2000. Subdivision of the cardiac Nkx-2.5 expression domain into myogenic and nonmyogenic compartments. Dev. Biol. 218: 326-340.

Ranganayakulu, G., Elliott, D., Harvey, R., and Olson, E. 1998. Divergent roles for NK-2 class homeobox genes in cardiogenesis in flies and mice. Development 125: 3037-3048.

Riefers, F., Walsh, E., Leger, S., Stainier, D., and Brand, M. 2000. Induction and differentiation of the zebrafish heart requires fibroblast growth factor 8 (fgf8/acerebellar). Development 127: 225-235.

Robb, L. 1997. Hematopoiesis: Origin pinned down at last? Curr. Biol. 7: R10-R12.

Rodriguez-Esteban, C., Capdevila, J., Economides, A., Pascual, J., Ortiz, A., and Izpisúa-Belmonte, J. 1999. The novel Cerlike protein Caronte mediates the establishment of embryonic left-right asymmetry. Nature 401: 243-251.

Rosenquist, G.C. 1966. A radioautographic study of labelled grafts in the chick blastoderm. Carnegie Institute of Washington Contributions to Embryology 38: 71-110.

Rosenquist, G.C., and DeHaan, R.L. 1966. Migration of Precardiac Cells in the Chick Embryo: A Radioautographic Study. Carnegie Inst. Washington Contrib. Embryol. 38: 111-121.

Salic, A., Kroll, K., Evens, L., and Kirschner, M. 1997. Sizzled: A secreted Xwnt8 antagonist expressed in the ventral marginal zone of Xenopus embryos. Development 124: 4739-4748.

Schlange, T., Andree, B., Arnold, H., and Brand, T. 2000. BMP2 is required for early heart development during a distinct time period. Mech. Dev. 91: 259-270.

Schneider, V. and Mercola, M. 2001. Wnt antagonism initiates cardiogenesis in Xenopus laevis. Genes \& Dev. 15: 304-315 (this issue).

Schoenwolf, G.C., García-Martínez, V., and Dias, M.S. 1992. Mesoderm movement and fate during avian gastrulation and neurulation. Dev. Dyn. 193: 235-248.

Schultheiss, T.M. and Lassar, A.B. 1997. Induction of chick cardiac myogenesis by bone morphogenetic proteins. Cold Spring Harbor Symp. Quant. Biol. 62: 413-419.

Schultheiss, T.M., Xydas, S., and Lassar, A.B. 1995. Induction of avian cardiac myogenesis by anterior endoderm. Development 121: 4203-4214.

Schultheiss, T., Burch, J., and Lassar, A. 1997. A role for bone morphogenetic proteins in the induction of cardiac myogenesis. Genes \& Dev. 11: 451-462.

Stern, H. and Hauschka, S. 1995. Neural tube and notochord promote in vitro myogenesis in single somite explants. Dev. Biol. 167: 87-103.

Sugi, Y. and Lough, J. 1994. Anterior endoderm is a specific effector of terminal cardiac myocyte differentiation of cells from the embryonic heart forming region. Dev. Dyn. 200: $155-162$.

Sundin, O. and Eichele, G. 1992. An early marker of axial pattern in the chick embryo and its respecification by retinoic acid. Development 114: 841-852.

Suzuki, A., Thies, R.S., Yamaji, N., Song, J.J., Wozney, J.M., Murakami, K., and Ueno, N. 1994. A truncated bone morphogenetic protein receptor affects dorsal-ventral patterning in the early Xenopus embryo. Proc. Natl. Acad. Sci. 91: 10255-10259.

Torres, M.A., Yang-Snyder, J.A., Purcell, S.M., DeMarais, A.A., McGrew, L.L., and Moon, R.T. 1996. Activities of the Wnt-1 class of secreted signaling factors are antagonized by the Wnt-5A class and by a dominant negative cadherin in early Xenopus development. J. Cell. Biol. 133: 1123-1137.

Tzahor, E. and Lassar, A.B. 2001. Wnt signals from neural tube block ectopic cardiogenesis. Genes \& Dev. 15: 255-260 (this issue).

Wang, S., Krinks, M., Lin, K., Luyten, F., and Moos, M. 1997. Frzb, a secreted protein expressed in the Spemann Organizer, binds and inhibits Wnt-8. Cell 88: 757-766.

Wilkinson, D.G. 1993. In situ hybridization. In Essential developmental biology, a practical approach (ed. C.D. Stern and P.W.H. Holland), pp. 257-274. IRL Press, Oxford.

Wu, X., Golden, K., and Bodmer, R. 1995. Heart development in Drosophila requires the segment polarity gene wingless. Dev. Biol. 169: 619-628.

Xu, Q., D'Amore, P., and Sokol, S. 1998. Functional and biochemical interactions of Wnts with FrzA, a secreted Wnt antagonist. Development 125: 4767-4776.

Yokouchi, Y., Vogan, K., Pearse II, R.V., and Tabin, C. 1999. Antagonistic signaling by caronte, a novel cerberus-related gene, establishes left-right asymmetric gene expression. Cell 98: 573-583.

Yutzey, K.E., Rhee, J.T., and Bader, D. 1994. Expression of the atrial-specific myosin heavy chain AMHC1 and the establishment of anteroposterior polarity in the developing chicken heart. Development 120: 871-883.

Zhu, L., Marvin, M., Gardiner, A., Lassar, A., Mercola, M., Stern, C., and Levin, M. 1999. Cerberus regulates left-right asymmetry of the embryonic head and heart. Curr. Biol. 9: 931-938. 


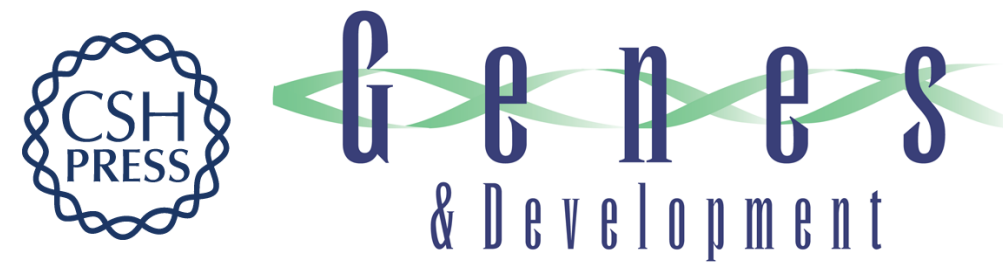

\section{Inhibition of Wnt activity induces heart formation from posterior mesoderm}

Martha J. Marvin, Giuliana Di Rocco, Aaron Gardiner, et al.

Genes Dev. 2001, 15:

Access the most recent version at doi:10.1101/gad.855501

References This article cites 76 articles, 36 of which can be accessed free at: http://genesdev.cshlp.org/content/15/3/316.full.htmI\#ref-list-1

License

Email Alerting

Receive free email alerts when new articles cite this article - sign up in the box at the top Service right corner of the article or click here.

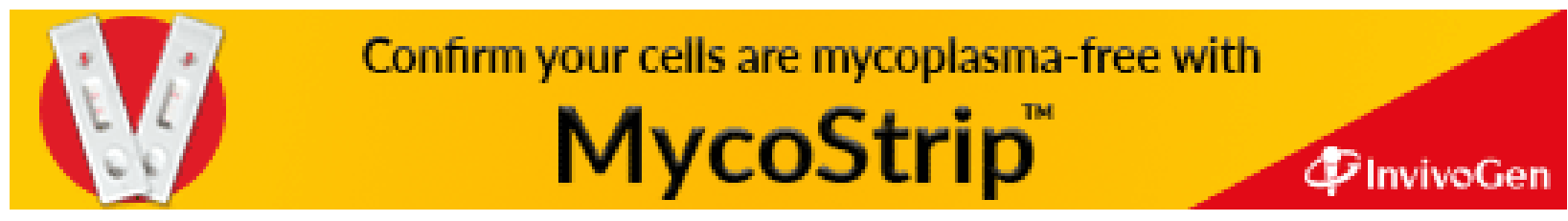

